\title{
An Empirical Study of the Social Economic Impact of Federal Polytechnic on its Host Community
}

\author{
G. K. Jenyo ${ }^{1}$ and Ola Adebayo ${ }^{2}$ \\ ${ }^{1}$ Department of Business Administration, Adeleke University Ede, Osun State-Nigeria \\ ${ }^{2}$ Department of Entrepreneurship, Joseph Ayo Babalola University, Ikeji-Arakeji, Osun State, Nigeria
}

\begin{abstract}
A polytechnic, sited in a metropolitan environment especially, is regarded among other things as a veritable citadel of learning and vehicle for social - economic emancipation of the people. Not only that the institution be a source of light into the darkness of ignorance, poverty and disease, but it will also provide gainful employment opportunities to its patrons, through its many linkages which will inevitably spring up overtime. Host communities to such institutions are usually seen as the primary beneficiaries, if the opportunities thus provided are effectively harnessed. The corollary also holds that if a gap exists by omission or commission, between the expected and actual outcomes regarding the project's impact on the host community, the credibility gap also widens. The wisdom in releasing their land for such projects. This study was undertaken to examine to what extent the Offa community was justified in hosting federal Polytechnic, vis-a-viz the economic impact that the latter is making on its host community. A survey research design was used while stratified sampling techniques were employed in selecting the sample, realizing the heterogeneous nature of the parameters employed. 50 questionnaires were distributed but only 34 were completed and returned which represented $68 \%$ response rate. Data collected were summarized using frequency tables while Pearson correlation analyses was further done to test the hypothesis that the establishment of Federal Polytechnic at Offa has not made any significant impact on the socio-economic life of Offa people. The finding showed that the impact so far made, is significant.
\end{abstract}

Keywords: Empirical study, host community, polytechnic, impact

\section{Introduction}

An act to establish polytechnics in various parts of the country to provide full-time courses in technology, applied sciences management and other fields of studies and to make provisions for the general administration of such polytechnics came into force on $25^{\text {th }}$ July, 1979. The product of these polytechnics serves as technicians in our industries and companies.

\section{Offa Town}

Offa is an important town in Yoruba history, the town was founded by Olalomi Olofagangan, a hunter prince of Oranmiyan descent who first settled in Oyo before moving to Offa. He reigned between 1397 and 1448. Offa served as the headquarters of the Ibolo speaking people in the $18^{\text {th }}$ century and its actions covered area like Oyan, Okuku, Ikirun, Osogbo, Ejigbo, Ilobu, Iresa/, Ede, Iwo to mention but few in the present day Osun State. Inhabited by one of the most industrious and educated people in Nigeria. Offa derived its name from Ofa (an arrow) used by
Olalomi Olofagangan for hunting. In present day Nigeria, Offa town is located in Kwara state with a population of 114,000 (as of 2005). The town is the second largest city in Kwara state (after Ilorin the state capital). The vegetation in Offa is savanna and the city is noted for its sweet potatoes among other food crops. The key religions practiced in the town are Islam and Christianity. Offa has a very rich cultural heritage in Yoruba land such as Onimaka, Moremi, Molepe, Ijakadi, festival and so on. The town lies along railroad from Lagos, the commercial capital of Nigeria, and Offa served as the railway terminus before the line was extended to Kano and Nguru in northern Nigeria.The tertiary institutions in the town include federal Polytechnic Offa, Kwara State College of Health Technology and the Nigeria Navy School of Health Sciences. There are also two private universities whose constructions are near completion. The present Olofa of Offa is HRM Oba Mufutau Gbadamosi Esuwoye ii, who upon assumption of office spent huge sum of personal money to give Offa a befitting and world rated Palace. In fact the palace has become of its size and architectural concepts. The praise name of Offa is "Ijakadi loro Offa" Yoruba phrase meaning 
"wrestling is our game". The city mescal is the peacock bird which is one of the most prominent exotic avian species. Offa people are industrious and enterprising. The town serves as commercial hub for its indigenes and the surrounding towns. The popular Owode market has grown to be ultra modern market. Due to the hospitality nature of Offa people, the town has grown in size and population. Offa is the headquarters of Offa local government, carved out of Oyun local government in 1991. It is one of the 16 local governments that constitute Kwara state.

\section{A Brief History of Federal Polytechnic Offa}

The Federal Polytechnic, Offa came into existence in 1992. A presidential pronouncement for its establishment was made at the Palace of His Royal Highness, Olofa of Offa, Oba Mustapha Olawoore Olanipekun Ariwaoye ii, by the then Military President, Ibrahim Babangida during a state visit in 1991.

Consequently, a local task force was then constituted by his royal highness, the Olofa under the Chairmanship of Alhaji Timiyu Olatinwo with six other eminent indigenes of Offa and Chief Ayotunde Raji as secretary.This local task force prepared the ground for easy take off of the polytechnic. It identified the premises of Olalomi comprehensive high school as a suitable temporary site and liased with identified landlords whose properties could be used by staff and students. The first Rector was Lady Engineer Taiwo Adeife Osemeikhian while Alh.Tunde Balogun was the Registrar. Other principal Officers include Dr. Rasaq Bello Deputy Rector, Mr. Olatore Deputy Registrar, Mr. P.K Adegbemi Acting Bursar, Mr. Olaoye Librarian.

There are five schools at federal polytechnic Offa namely;

-School of Engineering

-School of Applied sciences

-School of Environmental sciences

-School of Information Technology

-School of Business studies each headed by a Director.

Besides, there are two staff schools (primary and secondary) to cater for the children of the polytechnic workers. The school also has three guest houses for accommodation of visitors to the school and relaxation of the workers.

\section{Statement of the Problem}

It is common to mention finance, as the most significant factor plaguing the Nigeria case, Musa (2009) world want to suggest reordering of our emphasis, and in this regard, stemming of strike stands out as a major preoccupation, that is "getting the best out of our educational system" (Musa, 2009) whose product would not, as civil servants, engineers, with contractors to inflate contract swims for personal benefits; and would not be in any public office whatsoever to engage in corrupt practices. Cultism is a monster in the public polytechnic system which is believed in some quarters to be used by Chief Executives of Polytechnics to unleash terror on perceived enemies who might be students or lecturers.

\section{Research Objectives}

The objectives in this study are as follows;

(1) To assess the socio-economic profile of the various strata of Offa community, in the areas of consumption expenditures, patronage of hotel and banking facilities, as well as rental of shops and cafeteria spaces on campus and the general business life of the community before the inception of Federal Polytechnic Offa, using frequency counts and percentages as applicable as performance constructs.

(2) To assess the socio-economic profile of Offa community in the areas mentioned in (1) above along the same parameters, after the inception of Federal polytechnic Offa.

(3) To do statistical Pearson correlation analysis between 1 and 2 at 0.1 level ( 2 tailed).

(4) To present a valid conclusion and recommendation.

\section{Scope of the Study}

The study covers the impact of federal polytechnic Offa (Kwara State of Nigeria) in the following socioeconomic aspects of Offa community life. Injection of consumption expenditure of Federal Polytechnic workers, patronage of hotels and banking facilities as well as transportation services located in Offa. Others include shop and cafeteria allotment on campus of Offa community, activation of business activities in Offa and general enhancement of the image and status of Offa with the attendant linkage effects in several socio-economic areas of human endeavors. The time frame by the study is the period 2002-2012.

\section{Methodology}

The population for the study consisted of elements of various strata in the city of Offa, who in the opinion of the researcher were beneficiaries of Federal 
Polytechnic Offa from inception to date. These are pretty, small medium scale traders; landowners; hoteliers; bankers; contractors; transporters especially commercial motors cycles riders (okada); civil servants; and even the unemployed. About 50 respondents were sampled from the aforementioned strata using stratified sampling technique.

\section{Instrumentation}

Questionnaires were designed for data collection the instrument was validated for adequacy using a testretest reliability test which revealed a high correlation between the two measurements taken on the same population at different times.

\section{Result}

Data collected through the questionnaire were distilled using frequency tables.

Table1. Respondents income levels before and after the establishment of federal polytechnics Offa.

\begin{tabular}{lll}
\hline Income & Before Fed. Poly & After Fed . Poly \\
\hline N30, 000 & 19 & 12 \\
N 30,0001-60,000 & 12 & 10 \\
N -60,001-120,000 & 2 & 8 \\
N-120,001-240,000 & 1 & 3 \\
N250, 000 & - & 1 \\
Total & 34 & 34 \\
\hline
\end{tabular}

Table1 Respondents income levels before and after the establishment of federal polytechnics were 19 but this number was reduced to 12 after. Those of income range $\mathrm{N} 30,00$ to $\mathrm{N} 60,000$ were 12 before but reduced to 10 after. The respondent who earned between
N60,001 and N120,001 was 1 before but increased to 3 after while only one person emerged on earning N250,000 and above after the establishment of Federal polytechnic Offa respectively.

Table 2. Sizes of business of the respondent before and after The establishment of Federal polytechnic Offa. Size of Business.

\begin{tabular}{lll}
\hline Size of the Business & Before Fed. poly & After Fed. Poly \\
\hline No response & 16 & 17 \\
Small size & 11 & 4 \\
Medium size & 7 & 5 \\
large size & 0 & 8 \\
Total & 34 & 34 \\
\hline
\end{tabular}

In table 2,16 respondent before and 17 after the establishment of federal polytechnic did not respond. 11 of them had small size business before but reduce to 4 after. Those of medium size business were 7 before but reduce to 5 after. People had their business size increased to a large size after Federal Polytechnic was established.

The most probable reason for the large number of "no response" before and after (16 and 17 respectively) was that those respondents were not in business in the categories mentioned.

Table 3 (a) category of business practice before.

\begin{tabular}{lllll}
\hline & Frequency & Percent & Valid percent & Cumulative percent \\
\hline Valid no Response & 28 & 82.4 & 82.4 & 82.4 \\
Supplier & 4 & 11.8 & 11.8 & 94.1 \\
Contractor & 2 & 5.9 & 5.9 & 100.0 \\
Total & 34 & 100.00 & 100,00 & \\
\hline
\end{tabular}

Table 3 (b). Category of business practice after.

\begin{tabular}{lllll}
\hline & Frequency & Percent & Valid Percent & Cumulative percent \\
\hline Valid Percent & 16 & 47.1 & 47.1 & 82.4 \\
Supplier & 4 & 11.8 & 11.8 & 94.1 \\
Contractor & 14 & 41.2 & 41.2 & 100.0 \\
total & 34 & 100,00 & 100.00 & \\
\hline
\end{tabular}


Table 3 indicates a large number, 28 before and 16 after Federal Polytechnic was established respectively probably because they are not in the kind of Business indicated. It is remarkable that when the number of supplier remained 4 before and after Federal Polytechnic was established, contractor increased in number from 2 to 14 (before and after).

Table 4: Scope of transportation of the respondents before and after the establishment of federal polytechnic.

\begin{tabular}{|c|c|c|}
\hline Scope of Transportation & Before Fed. poly & After Fed. poly \\
\hline No response & 28 & 16 \\
\hline Within the city & 5 & 2 \\
\hline Campus shuttle & 1 & 16 \\
\hline Total & 34 & 34 \\
\hline
\end{tabular}

In Table 4 above, while the number of transporters decreased within the city (from 5 to 2 ) before and after, the campus shuttle increased from 1 to 16 so directly or indirectly it has provided employment for more people in the town and even in the revenue for Offa local govt.

Table 5 (a). Cafeteria Allotment on campus before.

\begin{tabular}{lllll}
\hline & Frequency & percent & Valid Percent & Cumulative Percent \\
\hline Valid SD & 11 & 32.4 & 32.4 & 32.4 \\
U & 3 & 8.8 & 8.8 & 41.2 \\
A & 15 & 44.1 & 44.1 & 85.3 \\
SA & 5 & 14.7 & 14.7 & \\
Total & 34 & 100.00 & 100.00 & \\
\hline
\end{tabular}

Table 5 (b). Cafeteria allotment on campus after.

\begin{tabular}{lllll}
\hline & Frequency & percent & Valid Percent & Cumulative Percent \\
\hline Valid SD & 7 & 20.6 & 20.6 & 20.6 \\
D & 1 & 2.9 & 2.9 & 23.5 \\
U & 1 & 26.5 & 26.5 & 26.5 \\
A & 9 & 26.5 & 26.5 & 52.9 \\
SA & 16 & 47.1 & 47.1 & \\
Total & 34 & 100.00 & 100.00 & 100.00 \\
\hline
\end{tabular}

Table 5 indicates that only $58 \%$ of the respondents either agreed Agreed that cafeteria allotment on campus was done for offa community members before federal polytechnic was established. This figure rose to $73 \%$ after the establishment of the federal polytechnic. Bearing in mind that a college (Olalomi comprehensive College) once existed on the campus before federal polytechnic came; the higher percentage was attributable to the impact of the polytechnic.

Table 6(a). Shop Allotment on campus before.

\begin{tabular}{lllll}
\hline & Frequency & Percent & Valid percent & Cumulative percent \\
\hline Valid SD & 12 & 35.3 & 35.3 & 35.3 \\
U & 3 & 8.8 & 8.8 & 44.1 \\
A & 14 & 41.2 & 41.2 & 85.3 \\
SA & 3 & 14.7 & 14.7 & - \\
Total & 34 & 100.00 & 100.00 & 100.00 \\
\hline
\end{tabular}


Table 6 (b). Shop allotment on campus after.

\begin{tabular}{lllll}
\hline & Frequency & Percent & Valid percent & Cumulative percent \\
\hline Valid SD & 7 & 20.6 & 20.6 & 20.6 \\
D & 1 & 2.9 & 2.9 & 23.5 \\
U & 2 & 5.9 & 5.9 & 29.4 \\
A & 8 & 23.5 & 23.5 & 52.9 \\
SA & 16 & 47.1 & 47.1 & - \\
Total & 34 & 100.00 & 100.00 & 100.00 \\
\hline
\end{tabular}

the same argument in Table 5 above for Table 6 where 24\% Agreed/Strongly Agreed that shop allotment was available on campus, after the

polytechnic establishment as against the $19 \%$ that agreed/ strongly Agreed before the polytechnic came.

Table 7(a). Banking facilities located around campus before.

\begin{tabular}{lllll}
\hline & Frequency & Percent & Valid Percent & Cumulative percent \\
\hline Valid SD & 11 & 32.4 & 32.4 & 32.4 \\
U & 6 & 17.6 & 17.6 & 50.0 \\
A & 14 & 41.2 & 41.2 & 91.2 \\
SA & 13 & 8.8 & 8.8 & -- \\
Total & 34 & 100.00 & 100.00 & 100.00 \\
\hline
\end{tabular}

Table 7(b). Banking facilities Located around campus after.

\begin{tabular}{lllll}
\hline & Frequency & Percent & Valid Percent & Cumulative percent \\
\hline Valid SD & 9 & 26.5 & 26.5 & 26.5 \\
U & 4 & 11.8 & 11.8 & 38.2 \\
A & 8 & 23.5 & 23.5 & 61.8 \\
SA & 13 & 38.2 & 38.2 & -- \\
Total & 34 & 100.00 & 100.00 & 100.00 \\
\hline
\end{tabular}

In Table 7, 62\% of respondents Agreed/strongly agreed to the presence of banking facilities around campus after the polytechnic came, as against the
$50 \%$ that similarly responded for the period before the establishment of Federal polytechnic.

Table 8(a). Transport providers- small bus (Korope).

\begin{tabular}{lllll}
\hline & Frequency & Percent & Valid Percent & Cumulative percent \\
\hline Valid SD & 9 & 26.5 & 26.5 & 26.5 \\
D & 1 & 2.9 & 2.9 & 29.4 \\
U & 6 & 17.6 & 17.6 & 47.1 \\
A & 16 & 47.1 & 47.1 & 94.1 \\
SA & 2 & 5.9 & 5.9 & -- \\
Total & 34 & 100.00 & 100.00 & 100.00 \\
\hline
\end{tabular}

Table 8(b). Transport providers especially small bus (Korope) After

\begin{tabular}{lllll}
\hline & Frequency & Percent & valid percent & Cumulative percent \\
\hline Valid SD & 6 & 17.6 & 17.6 & 17.6 \\
D & 1 & 2.9 & 2.9 & 20.6 \\
U & 2 & 5.9 & 5.9 & 26.5 \\
A & 11 & 32.4 & 32.4 & 58.8 \\
SA & 14 & 41.2 & 41.2 & - \\
total & 34 & 100.00 & 100.00 & 100.00 \\
\hline
\end{tabular}


In Table 8, the percentage that Agreed/strongly agreed to the presence of commercial small buses (Korope) increased from 53\% (before the polytechnic came) to $73 \%$ (after the establishment of the polytechnic.)

Table 9(a). Injection of consumption expenditure into Offa Community by federal polytechnic workers before.

\begin{tabular}{lllll}
\hline & Frequency & Percent & valid percent & Cumulative percent \\
\hline Valid SD & 9 & 26.5 & 26.5 & 26.5 \\
D & 2 & 5,9 & 5,9 & 32.4 \\
U & 9 & 26.5 & 26.5 & 58.8 \\
A & 10 & 29.4 & 29.4 & 88.2 \\
SA & 4 & 11.8 & 11.8 & -- \\
total & 34 & 100.00 & 100.0 & 100.00 \\
\hline
\end{tabular}

Table 9(b). Injection of consumption into Offa community by Federal polytechnic workers after.

\begin{tabular}{lllll}
\hline & Frequency & Percent & valid percent & Cumulative percent \\
\hline Valid SD & 9 & 26.5 & 26.5 & 26.5 \\
D & 1 & 2.9 & 2.9 & 2.9 \\
U & 4 & 11.9 & 11.8 & 41.2 \\
A & 5 & 14.7 & 14.7 & 55.9 \\
SA & 15 & 44.1 & 44.1 & -- \\
total & 34 & 100.00 & 100.0 & 100.00 \\
\hline
\end{tabular}

Table 9 indicate that percentage of respondent that Agreed/strongly Agreed to the fact that there were more increased from $41 \%$ (before) to $58 \%$ (after).

Table 10. Enhancing the socio-cultural development of Offa before.

\begin{tabular}{lllll}
\hline & Frequency & Percent & valid percent & Cumulative percent \\
\hline Valid SD & 8 & 23.5 & 23.5 & 23.5 \\
D & 5 & 14.7 & 14.7 & 38.5 \\
U & 2 & 5.6 & 5.9 & 44.1 \\
A & 6 & 17.6 & 17.9 & 61.8 \\
SA & 13 & 38.2 & 38.2 & -- \\
total & 34 & 100.00 & 100.0 & 100.00 \\
\hline
\end{tabular}

Table 10 talk about the polytechnic enhancing the social culture development of Offa community.
Respondents who Agreed/strongly Agreed with this view increased from $44 \%$ (before) to 55\% (after)

Table 11. Relationship between economic benefits before and after federal polytechnic.

(a) Discriminative statistics

\begin{tabular}{llcc}
\hline & Means & Standard Deviation & $\mathrm{N}$ \\
\hline Economic benefits before Fed. poly & 30.1176 & 10.3249 & 34 \\
Economic benefit after Fed. poly & 35.3824 & 12.5530 & 34 \\
\hline
\end{tabular}

(b) Correlations

\begin{tabular}{llll}
\hline & & $\begin{array}{l}\text { Economic benefits before } \\
\text { Red. poly }\end{array}$ & $\begin{array}{l}\text { Economic benefits } \\
\text { after Red. poly }\end{array}$ \\
\hline Economic benefits before Fed. Poly & $\begin{array}{l}\text { Pearson Correlation } \\
\text { Sip (2-tailed)N }\end{array}$ & 100034 & $512 * * 00234$ \\
Economic benefits before Fed. poly & $\begin{array}{l}\text { Pearson Correlation } \\
\text { Sip (2-tailed)N }\end{array}$ & $512 * * 00234$ & 10034 \\
\hline$* *$ correlation is significant at the 001 level (2-tailed) & &
\end{tabular}


Table 11a) summarized the survey findings using both Descriptive statistics and statistical analysis. Table 11(a) shows an increase in the mean and standard deviation before and after.

Table 11(b) is the Pearson correlation analysis. The strength of relationship, or the association between two variables is typically measured by the coefficient of correlation, whose value range from 1 (perfect negative correlation) to +1 (perfect positive correlation).

In this table the correlation coefficient ${ }^{\circledR}$ is 0.512 with is significant of the 0.01 level (2-tailed) ( $\mathrm{r}$ $=0.512, \mathrm{~N}=34, \mathrm{p}<0.01$ ).

\section{Findings and Discussion}

As stated earlier under the scope of the study, the areas of for investigation in this study are changes in the following: respondent income levels earned from their various business enterprises, participation in economic activities on campus, establishment of certain infrastructures, like bank and hotels in the community. Others are consumption expenditures incurred by polytechnic staff and the overall boost in the socio-economic staff of Offa. These changes were acclaimed to the next effect of the establishment of federal polytechnic Offa.

Specifically, it was found that the income levels of local populace increased, size of business enterprises changed from small to medium and large, while the status of business practices migrated from mere supply to contractor. On transport scene, the use of small bus (Korope) received a boost; partnership with polytechnic administration was enhanced in the cafeteria around campus received and boost while hotel sprang up to their own impact. Consumption expenditure of the polytechnic workers improved the economic activities of Offa community; lastly there is a significant enhancement of status socially and economically brought on Offa community as a result of the sitting of federal polytechnic at Offa.

\section{Conclusion and Recommendation}

Federal polytechnic Offa is of great benefit to Offa community, the landlords association was full of praises to the polytechnic activity because hitherto many houses were under lock and key, this has become things of the past. Demand for accommodation in Offa has increased tremendously. The night market in the community that close sometimes before $8 \mathrm{pm}$ is always full of activities till past $10 \mathrm{pm}$ especially when the school is in session. The only staff school established in the school (Fed. Poly) could not serve all the workers of the polytechnic hence the establishment of more private nursery and primary schools and colleges in the community this provide job for teachers that are employed in such schools, The polytechnic provide halls for entertainment for weddings and burial ceremonies at token fees during the weekends for the community. This Para is concluding with the following recommendations which if implemented would go a long way in fostering a healthier mutual relationship and sensitizing the Offa community or the need for greater cooperation with the federal polytechnic administration towards an accelerated development of Offa.

A gown to town programs should be instituted on campus, which would show case the polytechnic to the community. Outreach activities to undertake would cut across the polytechnic programs that can be adopted to benefit the local populace.

There could be free blood checkups by the polytechnic medical centre, the polytechnic security outfit could give counseling services for the commercial bus driver (korrope0 and motorcyclist (okada) and sponsor community based educational or cultural projects, even sporting events among the community members.

\section{References}

Asika, N (2001) Research metrology in Behavioral sciences. Longman Nig. Ltd Lagos.

Afolabi G.k, Adegbola P.O (2000) Scroll magazine Vol. 3 No 1 Jan. 2012

Offa at a glance 1970-2010

Krehbiel, B. L (2003) Basic business statistics concepts and Applications, perarson prentice hall n J 07458

Murray R.S and Stephen L.j. (2000) theory and problems of statistics, $3^{\text {rd }}$ Ed. Tata, McGraw-Hill pub. Co. Ltd New Delhi

Musa A. (2009) "Nigeria Universities -Tree without fruits" USA Africa Dialogue series March 23 pp1 